\title{
Antibody reaction of leptospirosis in asymptomatic feral boars, Thailand
}

\author{
Phirom Prompiram ${ }^{1}$, Kanaporn Poltep ${ }^{1}$ and Nongluck Sangkaew ${ }^{2}$
}

1. The Monitoring and Surveillance Center for Zoonotic Diseases in Wildlife and Exotic Animals, Faculty of Veterinary Science, Mahidol University, 999 Phuttamonthon 4 Rd., Salaya, Phutthamonthon, Nakhon Pathom 73170, Thailand; 2. Veterinary Research and Development Center Lower Northern Region, 9 Moo15 Phitsanulok-Lomsak Rd., Wangthong, Phitsanulok 65130, Thailand.

Corresponding author: Phirom Prompiram, e-mail: phirom.prm@mahidol.edu

Co-authors: KP: kanaporn.pol@mahidol.ac.th, NS: sambaithaow@hotmail.com

Received: 13-08-2019, Accepted: 17-10-2019, Published online: 29-11-2019

doi: www.doi.org/10.14202/vetworld.2019.1884-1887 How to cite this article: Prompiram P, Poltep K, Sangkaew N (2019) Antibody reaction of leptospirosis in asymptomatic feral boars, Thailand, Veterinary World, 12(11): 1884-1887.

\begin{abstract}
Aim: This study aimed to determine the proportion of exposure to leptospirosis and evaluate the degree of serovar antibody reaction in feral boars.

Materials and Methods: A total of 58 sera obtained from feral boars in Khao Prathab Chang Wildlife Breeding Center, Ratchaburi, Thailand, were screened for leptospirosis exposure by microscopic agglutination test, conducted with a reference panel of 23 pathogenic serovars and a non-pathogenic serovar.

Results: Overall exposure rate of $62.07 \%$ was found in the studied population. An antibody reaction presented in 18 of 24 leptospiral serovars. Among the seropositive, Ballum serovar showed predominant exposure in the feral boar population.

Conclusion: The results show a relatively high exposure to leptospirosis and the predominant serovar was Ballum followed by Canicola, the first finding in feral boars in Thailand. It has been revealed that feral boars act as a natural reservoir host of leptospirosis. There should be more concern about public health problems in leptospirosis arising where feral boars appear.
\end{abstract}

Keywords: Ballum serovar, Canicola serovar, feral boar, microscopic agglutination test, Thailand.

\section{Introduction}

Leptospirosis, a bacterial zoonotic disease, has shown a spatiotemporal incidence in the peoples of tropical regions with high temperature and humidity, including Thailand. During January-February 2019, one individual died among 186 cases of leptospirosis reported from 42 provinces around Thailand [1]. Moreover, the incidence of leptospirosis in Thailand is commonly involved with wildlife species, which are an important source of pathogenic serovars $[2,3]$.

The role of wildlife in harboring leptospirosis first focused on rodent species; however, several species of wildlife, including primate species, have been shown significantly in harboring leptospirosis $[3,4]$. To better understand the reservoir hosts or facilitating hosts of leptospirosis exposure in other wildlife, in particular, the feral boar should be of concern as a natural reservoir host, because of its feeding behavior on the ground that a leptospirosis endemic source, and they are considered highly mobile animals [5].

In the previous reports from both America and continental Europe, feral boars have been seen to harbor various predominant serovars of leptospirosis [6-9]. If

Copyright: Prompiram et al. Open Access. This article is distributed under the terms of the Creative Commons Attribution 4.0 International License (http://creativecommons.org/licenses/ by/4.0/), which permits unrestricted use, distribution, and reproduction in any medium, provided you give appropriate credit to the original author(s) and the source, provide a link to the Creative Commons license, and indicate if changes were made. The Creative Commons Public Domain Dedication waiver (http:// creativecommons.org/publicdomain/zero/1.0/) applies to the data made available in this article, unless otherwise stated. feral boars are exposed to the various leptospiral serovars, it could be another reservoir which could indicate the predominant serovar that might be of public significance.

Therefore, this study aimed to determine the extent of exposure to leptospirosis and to evaluate the predominant serovar in feral boars for the $1^{\text {st }}$ time of Thailand.

\section{Materials and Methods}

\section{Ethical approval}

The procedures of restraint and blood collection for the feral boars were approved by the Mahidol University Application for Permission for Animal Care and Use: MUVS-2009-05, Faculty of Veterinary Science, Mahidol University, Thailand.

\section{Study site}

Feral boars were collected inside Khao Prathab Chang Wildlife Breeding Center, Ratchaburi, which is located in the western part of Thailand. This center was originally an animal shelter that contained captive wildlife, including conserved primates, tigers, bears, deer, and several species of wild bird and feral animals, particularly free-ranging rodents and boar. Feral boar was first an illegal animal seized and then inbreeding to increase the population into about 200-250 individuals that were distributing inside the restricted area, approximately 900 acres around the captive animal area. Serum of asymptomatic feral boar was submitted by 58 individuals. All serum collections had been stored using cryopreservation $\left(-80^{\circ} \mathrm{C}\right)$ at the Faculty of Veterinary Science, Mahidol University, since 2009 until laboratory testing. 


\section{Microscopic agglutination test (MAT)}

At the Veterinary Research and Development Center, Northern Lower Zone (Phitsanulok, Thailand), MAT was following the Manual of Diagnostic Tests and Vaccines for Terrestrial Animals for leptospirosis [10] with a reference panel of 23 pathogenic serovars and a non-pathogenic serovar, Patoc was performed. During the screening test, individual serum was diluted in phosphate-buffered saline and an equal volume of antigen was added by the final concentration was 1:100 following OIE recommendation and then, the mixtures were incubated at $30^{\circ} \mathrm{C}$ for $1.5 \mathrm{~h}$. The antibody reactions were examined using the dark-field microscope at least $50 \%$ agglutination with each antigen considerable as the endpoint. The sample was showing the reaction for at least one serovar, considerable the seropositive for specific serovar. The significant of the test was determined by the Chisquare test, at $\mathrm{p}<0.05$.

\section{Results and Discussion}

This study is a preliminary documented the leptospirosis in feral boar of Thailand. Khao Prathab Chang Wildlife Breeding Center was established for conservative wildlife and resting the illegal animal with various species of wildlife. Among animal species, feral boar is one significant species in this area due to widespread and close to natural environment. To determine the proportion of leptospirosis exposure in feral boar, MAT was performed to detect the reactive antibody of leptospirosis. It is significant to note that the present study used the endpoint titer of 1:100, a single dilution as recommended by OIE [10] for screening test, although, the positive was set at titer of equal or more than 1:100. However, other study in livestock of Thailand, the positive by MAT was considered at less than dilution for the titer of equal or more than 1:50 [11]. Therefore, the proportion of leptospire exposure in this study is likely underestimated due to some feral boar that was positive reaction at less dilution not tested.

The overall exposure rate of the asymptomatic feral boars here was 36 of $58(62.07 \% ; 95 \%$ confidence interval [CI] 60.94-63.20). This is considered a high exposure rate among wildlife species [3,4]. It certainly demonstrates a natural harboring source of the leptospiral bacteria in feral boars. From the previous studies in feral boars, the exposure rate is different when considering the different geographic location or the reference panel of antigens used $[6,8,9,12]$. However, a high exposure rate is further associated with host susceptibility since feral boars live close to a contaminated environment, so there is the possibility of exposure to leptospires throughout their lifespan with a wide range distribution $[5,13]$. This study supports the role of a natural reservoir host of leptospirosis showing 36 feral boars which were found seropositive with 18 of 24 serovars (Table-1). They were infected naturally and reflect the serovars circulating in the geographic habitat. From the different geographic areas of a previous study in feral boars, a variety of predominant serovars, including Bratislava (serogroup Australis), Pomona, and Tarassovi were found, and this may reflect the specificity of an individual area. In addition, a panel of non-pathogenic serovars using Patoc was tested. It was rarely reactive, due to non-specific immune defense, and the test was completely clear. Nevertheless, infection is likely to be found in a resistance incompetent host or with a high level of organism load that results in finding reactive antibodies. This study consistently found that the test was negative to Patoc, agreeing with the study using MAT in Thai livestock which found seronegativity among buffaloes, sheep, and goats [11]. However, Patoc is usually used to develop the agglutination test to screen for leptospire infection showing less specificity than MAT, a gold standard for detecting immune response to leptospirosis that was performed in this study.

In these study findings (Table-1), the predominant leptospirosis exposure $(\mathrm{n}=18)$ higher than others $(\mathrm{p} \leq 0.05)$ was the Ballum serovar with $31.03 \%$ (95\% CI 29.90-32.17), showing a difference from serovars found in other feral boars from the previous studies and moreover different from that found in the pig farms of Thailand, which is the Ramarum serovar $[11,14]$. This finding is the first report of the predominant serovar being Ballum in feral boars and furthermore in the country of Thailand. In the previous studies, the Ballum serovar has been isolated from the African giant pouched rat (Cricetomys gambianus) urine and is frequently found as associate evidence with the positive reaction antibody in humans $[15,16]$. It reveals that Ballum, the predominant serovar of leptospirosis found in this study, has been a significant serovar either harboring the chain of infection with rodent species or having an effect on public health problems. Moreover, the serovar with a high antibody reaction $(\mathrm{n}=13$, Table- 1$)$ was the Canicola serovar with $22.41 \%$ (95\% CI 21.28-23.55). The previous study has shown Canicola serovar typing by pulsed-field gel electrophoresis, variable number tandem repeat analysis, and single-enzyme amplified fragment length polymorphism in canines and porcine that were identical with bovines [17]. However, this serovar is usually found to have more exposure in canines than porcine with feral boars as a member, and moreover, Canicola serovar can be found in various animal reservoirs and humans, as implicated by antibody detection [18]. It indicates that possibly the host range of Canicola serovar has several animal reservoir hosts and causes pathogenicity in humans, despite one source being harbored by either canine or porcine.

Therefore, leptospirosis should be a concern in specific areas where feral boars appear to be a source of a zoonosis. Although the impact of the health problem on the public in the chain of infection is restrictedly needed by an individual serovar, it is possibly 
Table-1: The overall seropositive by using microscopic agglutination test (MAT) in 36 out of 58 wild boars from Khao Prathab Chang Wildlife Breeding Center, Thailand.

\begin{tabular}{|c|c|c|c|c|}
\hline \multirow[t]{2}{*}{ Serovar* } & \multirow[t]{2}{*}{ n (seropositive) } & \multirow[t]{2}{*}{ Exposure rate (\%) } & \multicolumn{2}{|c|}{$95 \% \mathrm{CI}$} \\
\hline & & & lower & upper \\
\hline Ballum & 18 & 31.03 & 29.90 & 32.17 \\
\hline Canicola & 13 & 22.41 & 21.28 & 23.55 \\
\hline Djasiman & 9 & 15.52 & 14.39 & 16.65 \\
\hline Shermani & 8 & 13.79 & 12.66 & 14.93 \\
\hline Cynopteri & 6 & 10.34 & 9.21 & 11.48 \\
\hline Bratislava & 5 & 8.62 & 7.49 & 9.75 \\
\hline Hebdomadis & 5 & 8.62 & 7.49 & 9.75 \\
\hline Ranarum & 5 & 8.62 & 7.49 & 9.75 \\
\hline Grippotyphosa & 4 & 6.90 & 5.76 & 8.03 \\
\hline Javanica & 4 & 6.90 & 5.76 & 8.03 \\
\hline Autumnalis & 3 & 5.17 & 4.04 & 6.30 \\
\hline Bataviae & 3 & 5.17 & 4.04 & 6.30 \\
\hline Celledoni & 3 & 5.17 & 4.04 & 6.30 \\
\hline Manhao & 3 & 5.17 & 4.04 & 6.30 \\
\hline Mini & 3 & 5.17 & 4.04 & 6.30 \\
\hline Pomona & 3 & 5.17 & 4.04 & 6.30 \\
\hline Pyrogenes & 1 & 1.72 & 0.59 & 2.86 \\
\hline Tarassovi & 1 & 1.72 & 0.59 & 2.86 \\
\hline
\end{tabular}

* The negative response found the antibody to Icterohaemorrhagiae, Louisiana, Panama, Patoc, Sarmin and Sejroe

transmitted by other animal species such as companion animals or rats, which are more closely related to humans than feral boars. However, this study supports that feral boars play a role by naturally harboring the pathogenic serovars for leptospirosis, despite the predominant serovars depending on an individual area of the feral boar habitat.

\section{Conclusion}

From this study, feral boars were seen to have high leptospiral exposure, confirming the source of various serovars representing the predominant, depending on the circulation of individual serovars in their habitat. The knowledge of serovars in feral boars is the baseline for further awareness, preparedness, and prevention of leptospirosis in public. More details are needed about the relative incidence of leptospirosis in the public and feral boars.

\section{Authors' Contributions}

$\mathrm{PP}$ and KP collected and stored the feral boar serum. NS assisted in conducting the MAT. PP and KP partially scientifically analyzed the result, drafted, and revised the manuscript. All authors read and approved the final manuscript.

\section{Acknowledgments}

The authors are thankful to Dr. Duangjai Suwancharoen for kind help, the Monitoring and Surveillance Center for Zoonotic Diseases in Wildlife and Exotic Animals, Faculty of Veterinary Science, Mahidol University, Thailand for facilitating the collection of the excess serum, Khan Prathab Chang Wildlife Breeding Center, the Department of National Parks, Wildlife and Plant Conservation for permitting and restraining during sample collection, and the Veterinary Research and Development Center,
Northern Lower Zone for collaborating in leptospirosis diagnosis. The collection part of this study work is a part of the project "Seroprevalence of Japanese encephalitis virus in domestic pigs and some ardeid birds, herons, and egrets, in the area of Thailand" (grant number 148/2552) and is funded by Mahidol University, Thailand.

\section{Competing Interests} interests.

The authors declare that they have no competing

\section{Publisher's Note}

Veterinary World remains neutral with regard to jurisdictional claims in published institutional affiliation.

\section{References}

1. Bureau of Epidemiology. (2019) Leptospirosis. Available from: https://www.boe.moph.go.th/boedb/d506_1/ds_wk2pdf_ en.php?ds=43\&yr=62. Last accessed on 12-08-2019.

2. Petrakovsky, J., Bianchi, A., Fisun, H., Nájera-Aguilar, P. and Pereira, M.M. (2014) Animal leptospirosis in Latin America and the Caribbean countries: Reported outbreaks and literature review (2002-2014). Int. J. Environ. Res. Public Health, 11(10): 10770-10789.

3. Doungchawee, G., Phulsuksombat, D., Naigowit, P., Khoaprasert, Y., Sangjun, N., Kongtim, S. and Smythe, L. (2005) Survey of leptospirosis of small mammals in Thailand. Southeast Asian J. Trop. Med. Public Health, 36(6): 1516-1522.

4. Thayaparan, S., Robertson, I.D. and Abdullah, M.T. (2015) Serological and molecular detection of Leptospira spp. from small wild mammals captured in Sarawak, Malaysia. Malays. J. Microbiol., 11(1): 93-101.

5. Linares, M., Hicks, C., Bowman, A.S., Hoet, A. and Stull, J.W. (2018) Infectious agents in feral swine in Ohio, USA (2009-2015): A low but evolving risk to agriculture and public health. Vet. Anim. Sci., 6(2018): 81-85.

6. Chatfield, J., Milleson, M., Stoddard, R. and Galloway, R. (2013) Serosurvey of leptospirosis in feral hogs (Sus scrofa) 
in Florida. J. Zoo. Wildl. Med., 44(2): 404-407.

7. Majetic, Z.S., Galloway, R., Sabljic, E.R., Milas, Z., Perko, V.M., Habus, J., Margaletic, J., Pernar, R. and Turk, N. (2014) Epizootiological survey of small mammals as Leptospira spp. reservoirs in Eastern Croatia. Acta. Trop., 131(1): 111-116.

8. Zmudzki, J., Jablonski, A., Nowak, A., Zebek, S., Arent, Z., Bocian, L. and Pejsak, Z. (2016) First overall report of Leptospira infections in wild boars in Poland. Acta Vet. Scand., 58(1): 3.

9. Vengust, G., Lindtner-Knific, R., Zele, D. and Bidovec, A. (2008) Leptospira antibodies in wild boars (Sus scrofa) in Slovenia. Eur. J. Wildl. Res., 54(4): 749-752.

10. World Organization for Animal Health, (Office International des Épizooties-OIE). (2014) Leptospirosis. In: Manual of Diagnostic Tests and Vaccines for Terrestrial Animals. Office International des Épizooties, Paris.

11. Suwancharoen, D., Chaisakdanugull, Y., Thanapongtharm, W. and Yoshida, S. (2013) Serological survey of leptospirosis in livestock in Thailand. Epidemiol. Infect., 141(11): 2269-2277.

12. Vale-Goncalves, H.M., Cabral, J.A., Faria, M.C., NunesPereira, M., Faria, A.S., Veloso, O., Vieira, M.L. and PaivaCardoso, M.N. (2015) Prevalence of Leptospira antibodies in wild boars (Sus scrofa) from Northern Portugal: Risk factor analysis. Epidemiol. Infect., 143(10): 2126-2130.

13. Pedersen, K., Pabilonia, K.L., Anderson, T.D., Bevins, S.N., Hicks, C.R., Kloft, J.M. and Deliberto, T.J. (2015) Widespread detection of antibodies to Leptospira in feral swine in the United States. Epidemiol. Infect., 143(10):
2131-2136.

14. Chadsuthi, S., Bicout, D.J., Wiratsudakul, A., Suwancharoen, D., Petkanchanapong, W., Modchang, C., Triampo, W., Ratanakorn, P. and Chalvet-Monfray K. (2017) Investigation on predominant Leptospira serovars and its distribution in humans and livestock in Thailand, 2010-2015. PLoS Negl. Trop. Dis., 11(2): e0005228.

15. Assenga, J.A., Matemba, L.E., Muller, S.K., Mhamphi, G.G. and Kazwala, R.R. (2015) Predominant leptospiral serogroups circulating among humans, livestock and wildlife in Katavi-Rukwa ecosystem, Tanzania. PLoS Negl. Trop. Dis., 9(3): e0003607.

16. Kessy, M.J., Machang'u, R.S. and Swai, E.S. (2010) A microbiological and serological study of leptospirosis among pigs in the Morogoro municipality, Tanzania. Trop. Anim. Health Prod., 42(3): 523-530.

17. Miraglia, F., de Morais, Z.M., Dellagostin, O.A., Seixas, F.K., Freitas, J.C., Zacarias, F.G.S., Delbem, A.C., Ferreira, T.S.P., Souza, G.O., Hartskeerl, R.A., Vasconcellos, S.A. and Moreno, A.M. (2012) Molecular and serological characterization of Leptospira interrogans serovar canicola isolated from dogs, swine and bovines in Brazil. Trop. Anim. Health Prod., 45(1): 117-121.

18. Mgode, G.F., Machang'u, R.S., Mhamphi, G.G., Katakweba, A., Mulungu, L.S., Durnez, L., Leirs, H., Hartskeerl, R.A. and Belmain, S.R. (2015) Leptospira serovars for diagnosis of leptospirosis in humans and animals in Africa: Common Leptospira isolates and reservoir hosts. PLoS Negl. Trop. Dis., 9(12): e0004251. 